\title{
Vector ecology and susceptibility in a malaria- endemic focus in southern Islamic Republic of Iran
}

M. Soleimani-Ahmadi, ${ }^{1,2}$ H. Vatandoost, ${ }^{7}$ M. Shaeghi, ${ }^{1}$ A. Raeisi, ${ }^{3}$ F. Abedi, ${ }^{2}$ M.R. Eshraghian, ${ }^{1}$ A. Madani, ${ }^{2}$ R. Safari, ${ }^{4}$ M. Shahi, ${ }^{2}$ A. Mojahedi ${ }^{4}$ and F. Poorahmad-Garbandi ${ }^{4}$

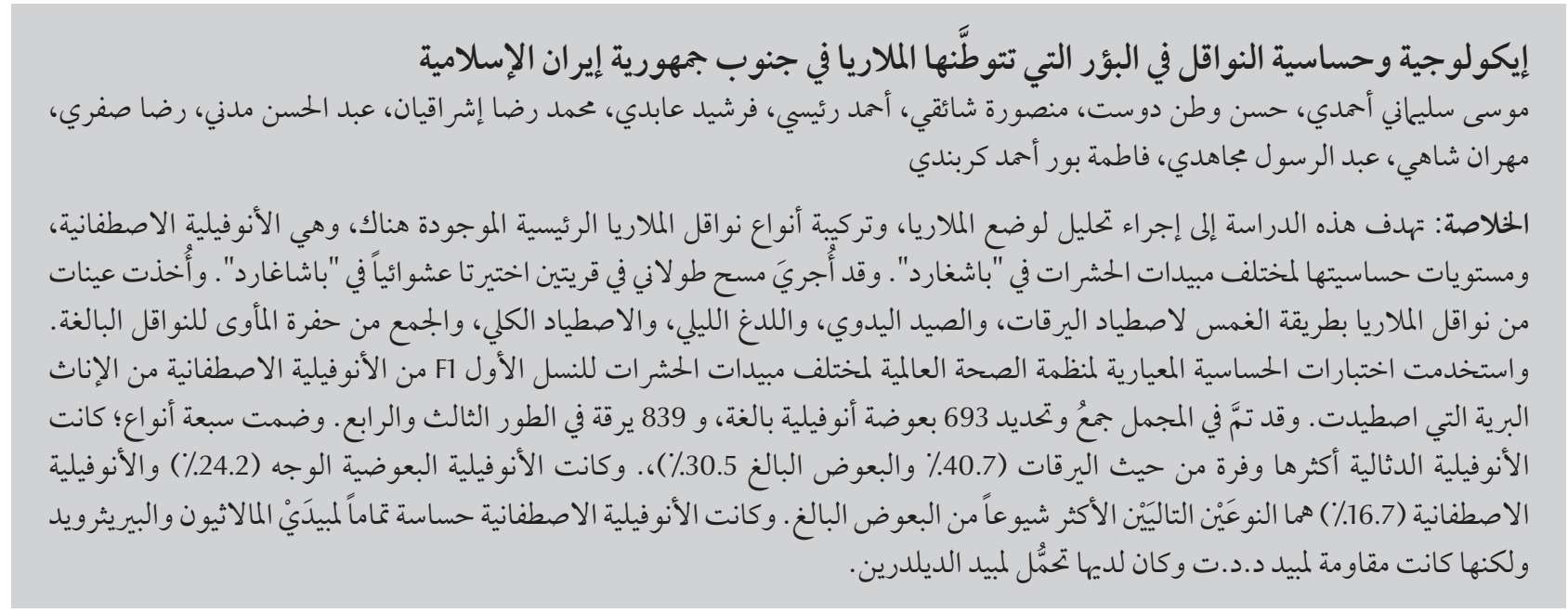

ABSTRACT This study aimed to carry out a malaria situation analysis, species composition and susceptibility levels of the main malaria vector, Anopheles stephensi, to different insecticides in Bashagard. A longitudinal survey was conducted in 2 randomly selected villages in Bashagard. Malaria vectors were sampled by dipping method for the larvae and hand catch, night-biting catch, total catch, and shelter pit collection for the adults. Standard WHO susceptibility tests were used for a variety of insecticides on F1 progeny of An. stephensi reared from wild-caught females. In total, 693 adult anopheline mosquitoes and 839 third and fourth-instar larvae were collected and identified. They comprised 7 species; the most abundant adult and larvae anopheline mosquito was An. $d$ thali ( $40.7 \%$ and $30.5 \%$ respectively). An. culicifacies (24.2\%) and An. stephensi (16.7\%) were the next most common species for adult mosquitoes. An. stephensi was fully susceptible to malathion and pyrethroid insecticides but resistant to DDT and tolerant to dieldrin.

\section{Écologie et sensibilité des vecteurs dans un foyer d'endémie palustre dans le sud de la République islamique d'Iran}

RÉSUMÉ L'étude visait à réaliser une analyse de la situation du paludisme, de la composition des espèces et des niveaux de sensibilité du vecteur principal du paludisme, Anopheles stephensi, à différents insecticides dans le district de Bashagard. Une enquête longitudinale a été menée dans deux villages du district de Bashagard sélectionnés aléatoirement. Des prélèvement ont effectués sur des vecteurs du paludisme par la méthode d'immersion pour les larves et à la main, par piqûre nocturne, par capture totale, et par capture dans des fosses-abris pour les adultes. Les tests de sensibilité normalisés de l'Organisation mondiale de la Santé ont été utilisés pour plusieurs insecticides sur la progéniture $\mathrm{F} 1 \mathrm{~d}$ 'An. stephensi élevée à partir de femelles sauvages capturées. Au total, 693 moustiques anophèles adultes et 839 larves au troisième et quatrième stades ont été capturés puis identifiés. Les échantillonscomptaient 7 espèces ; le moustique anophèle sous sa forme adulte et larvaire le plus fréquent était An. dthali (40,7 \% et 30,5\% respectivement). Les espèces qui arrivaient en deuxième position sous leur forme adulte étaient An. culicifacies (24,2 \%) et An. stephensi (16,7 \%). Les spécimens d'An. stephensi étaient pleinement sensibles au malathion et aux insecticides pyréthrö̈des mais étaient résistants au dichlorodiphényltrichloroéthane et tolérants à la dieldrine.

${ }^{7}$ Department of Medical Entomology and Vector Control, School of Public Health \& National Institute of Health Research, Tehran University ofMedical Sciences, Tehran, Islamic Republic of Iran (Correspondence to H. Vatandoost: hvatandoost1@yahoo.com,vatando@tums.ac.ir). ${ }^{2}$ Infectious Diseases Research Centre, Hormozgan University of Medical Sciences, Bandar Abbas, Islamic Republic of Iran. ${ }^{3}$ Department of Malaria Control, Ministry of Health and Medical Education, Tehran, Islamic Republic of Iran. ${ }^{4}$ Hormozgan Health Centre, Hormozgan University of Medical Sciences, Bandar Abbas, Islamic Republic of Iran.

Received: 02/06/10; accepted: 31/10/10 


\section{Introduction}

Malaria is still a major endemic disease in foci located in the south and south-east of the Islamic Republic of Iran. These areas include the provinces of Sistan and Baluchistan, Hormozgan and Kerman [1].

In this part of the country 6 anopheline mosquitoes are known to be the malaria vectors including: Anopheles culicifacies, An. stephensi, An. dthali, An. fluviatilis, An. superpictus and An. pulcherrimus [2].

These south and south-east provinces have less than $5 \%$ of the Islamic Republic of Iran's total population, but more than $96 \%$ of the total incidence of malaria cases in the whole country with Plasmodium vivax and $P$. falciparum both being present [3]. Hormozgan province is highly endemic for malaria as it has $38 \%$ of all malaria cases reported in the country [3]. In this province approximately 625 cases of malaria were reported during 2009, 33\% of which were reported in Bashagard district alone, although the district comprises only $2.2 \%$ of the total population of Hormozgan (Hormozgan Health Center, unpublished data, 2009). Geographical location, tropical climate and socioeconomic conditions make it an appropriate condition for occurrence and persistent transmission of malaria in this district.

Previous studies on anopheline mosquitoes have reported the presence of 12 species in Hormozgan province, at least 5 of which may be involved in malaria transmission [4]. An. stephensi is one of the main malaria vectors in the province [5] and insecticide resistance monitoring of An. stephensi has been carried out regularly. Resistance of An. stephensi to DDT, dieldrin and malathion was reported in 1957, 1960 and 1976 respectively [6-8]. Recent studies have shown that An. stephensi from Bandar Abbas region is the most resistant to
DDT [9]. In addition An. stephensi has been reported resistant to DDT in Afghanistan, India, Pakistan, Iraq, Oman, United Arab Emirates and Saudi Arabia [10]. In the Islamic Republic of Iran, after the appearance of malathion resistance in An. stephensi, propoxur was substituted in 1978 and was used for the next 13 years [11]. In recent years, pyrethroids have been used for residual spraying in malaria control programmes. From 1990 till 2009, pyrethroid resistance monitoring showed that almost all tested $A n$. stephensi were susceptible $[12,13]$.

Studies conducted in various parts of the world have shown that the use of nets treated with insecticides is an effective tool against mosquito bites and in reducing morbidity and mortality due to malaria [14]. The Iranian National Malaria Control Programmes currently relies on strategies targeting mosquito vector control, which involve the use of long-lasting insecticidal nets (LLINs).

In Bashagard, which is severely affected by malaria, access to health services is limited and medication often inappropriate. Thus insecticide treated mosquito nets (ITNs) present an attractive option that can effectively complement the main malaria control strategy based on early diagnosis and prompt treatment [15]. Therefore Bashagard district was selected for the evaluation of LLINs in south of Iran.

However, before interventions are recommended for use in malaria vector control, data on the prevalence and susceptibility of the vector are needed. The objective of this pre-intervention study therefore was to assess the distribution of anopheline species, their composition and the susceptibility of An. stephensi in Bashagard district.

\section{Methods}

\section{Study area}

The study was conducted from July 2009 to July 2010 in Bashagard district. Annual parasite index (API) was 6.5/1000 in 2009 (Hormozgan Health Centre, unpublished data). The district is located $26^{\circ} 04^{\prime}-26^{\circ} 58^{\prime} \mathrm{N}$ latitude and $57^{\circ} 23^{\prime}-59^{\circ} 02^{\prime} \mathrm{E}$ longitude. Most of Bashagard is mountainous with deep valleys and steep slopes. The district has an area of $10000 \mathrm{~km}^{2}$ and a population of 31293 . Then majority of the population live on the hills and foot-hills and most houses are made of straw. The villages are scattered, thinly populated, difficult to approach and unreachable by road during floods. The socioeconomic condition of the villagers is poor and the people depend solely on husbandry of goats and other animals.

\section{Selection of study villages}

On the basis of available epidemiological data and average malaria incidence rate in Hormozgan health centre, 14 villages in 2 arms were selected for implementation of the use of LLINs. These villages were selected randomly in 2 clusters, and assigned to either LLIN or controls with untreated nets. Cluster 1 (LLINs) comprised 8 villages (population 1653) and cluster 2 (untreated net) had 6 villages (population 1554). A suitable village for entomological study was selected in each cluster; Tisur $\left(58^{\circ} 15^{\prime} \mathrm{N}, 26^{\circ} 30^{\prime} \mathrm{E}\right.$; 840 metres above sea level) in cluster 1 and Daranar $\left(58^{\circ} 23^{\prime} \mathrm{N}, 26^{\circ} 15^{\prime} \mathrm{E}\right.$; 420 metres above sea level) in cluster 2 (Figure 1).

\section{Mosquito collection}

To study the anopheline mosquito fauna, sampling was carried out in 2 villages in Bashagard district. Monthly indoor pyrethrum space spray catches were performed early in the morning, in a total of 8 fixed human shelters (4 in the treatment and 4 in the control zone) before distribution of LLINs and the start of mosquito activity. In addition, adult mosquitoes resting indoors were collected between 07:00 and 08:00 using an aspirator and flashlight. 


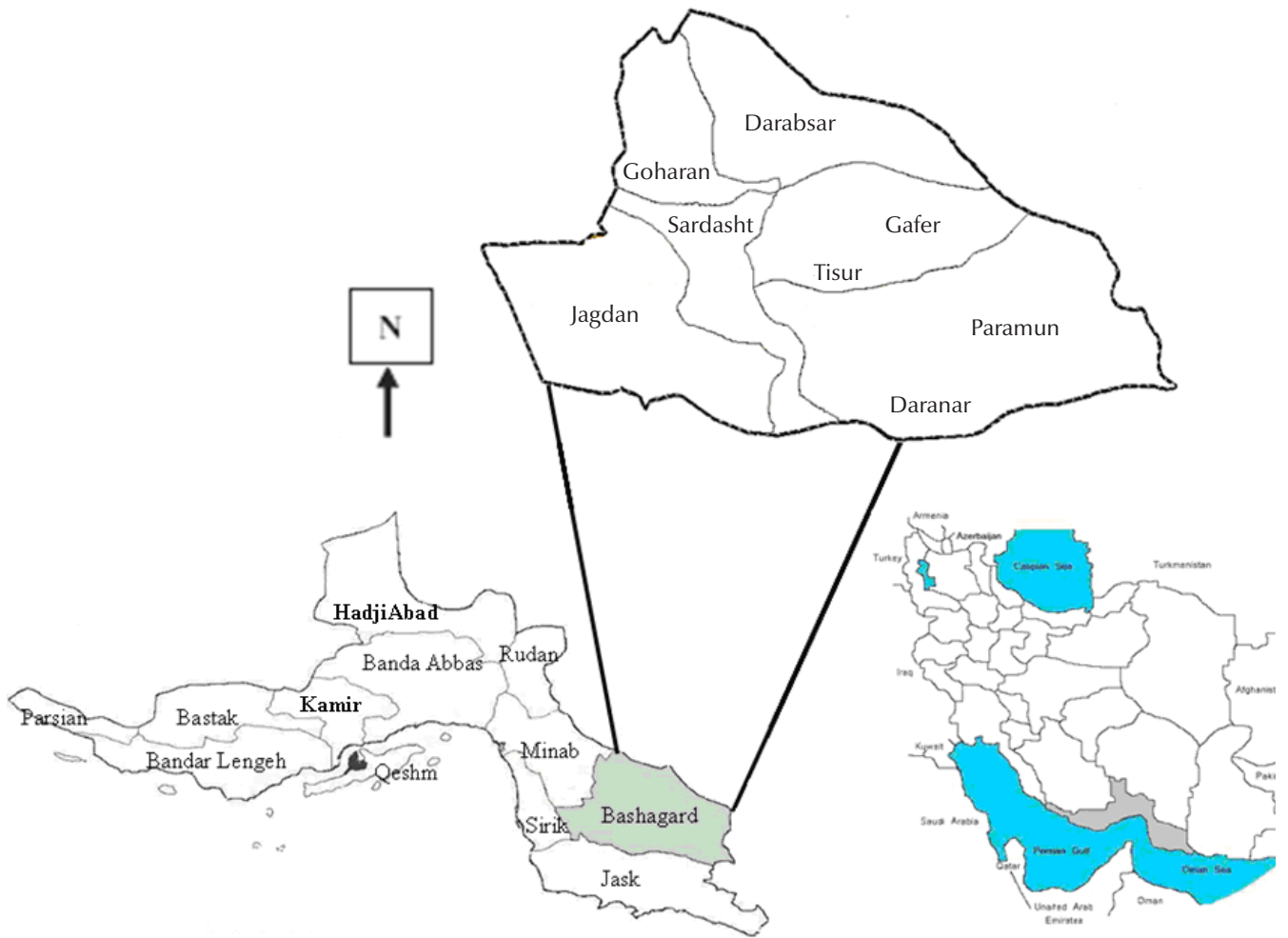

Figure 1 Map showing the provinces of the Islamic Republic of Iran, highlighting the position of Hormozgan Province (grey shaded area) and Bashagard district (study villages )

Attempts were also made to obtain adult mosquitoes by hand catch, nightbiting catch on donkeys, using aspirators, or by rearing immature stages collected in aquatic habitats. Larvae were collected from breeding places close to the adult collection sites using the standard dipping method [16]. All larvae were collected from a large variety of sun-exposed breeding sites such as seepages, streams, river banks, drying river beds and pools. The Anopheline larvae are often found in the vicinity of human dwellings, around each village. The larvae were preserved in lactophenol and the microscopic slides of the preserved larvae were prepared using Berlese medium. Both fourth instar larvae and adults were identified using the morphological characters standard key [17].

\section{Susceptibility to insecticides}

Since An. stephensi is the main disease vector in the Hormozgan province, insecticide tests were performed only on this species. Susceptibility status to the insecticides was determined using the standard World Health Organization (WHO) method for adults [18]. Immature stages were collected from different aquatic habitats in Bashagard district and transported to a temporary insectary, fed with Bemax and then adults that emerged were tested. The tests were carried out on 2-3-day-old, sugar-fed adults. Batches of 25 fully sugar-fed females were exposed to a diagnostic dose of DDT 4\%, dieldrin $0.4 \%$, malathion $5 \%$, permethrin $0.75 \%$, deltamethrin $0.05 \%$, lambda-cyhalothrin $0.05 \%$ and cyfluthrin $0.15 \%$.

In the Islamic Republic of Iran, currently only pyrethroids are being applied in malaria vector control, but DDT and dieldrin were tested because they have been intensively used for vector control in the past. Moreover, they can be used for exploring cross-resistance with other insecticides, such as pyrethroids.

The exposure time to organophosphate and pyrethroid insecticides was
1 hour. To monitor the susceptibility status over time, the lethal time $\left(\mathrm{LT}_{50}\right)$ value of An. stephensi to DDT and dieldrin was determined using a log-probit regression line. Mosquitoes were exposed for different logarithmic times to discriminative doses of insecticide-impregnated papers. After exposure, mosquitoes were maintained at $25 \pm 2{ }^{\circ} \mathrm{C}$ and $70 \%-80 \%$ relative humidity for 24 hours, supplied with $10 \%$ sugar solution and mortality was read after this 24 hour recovery period. All observed deaths at different time intervals were corrected using Abbott's formula when necessary [19]. $\mathrm{LT}_{50}$ and $\mathrm{LT}_{90}$ were determined using log-time and probit mortality regression [20].

\section{Results}

\section{Anopheles species composition and abundance}

A total of 693 adult anopheline mosquitoes were collected during the study. 
The species caught were: An. culicifacies, An. dthali, An. fluviatilis, An. stephensi, An. superpictus, An. moghulensis and An. turkhudi (Table 1). An. dthali was the predominant vector species in each of the 2 villages. In Tisur $39.8 \%$ of the 347 specimens and in Daranar $43.6 \%$ of 346 specimens caught were An. dthali (Figure 2). An. fluviatilis was the least abundant of the 7 species and found in the villages (Table 1). Vector species, An. culicifacies, An. dthali, An. stephensi and $A n$. superpictus were collected by various different methods but An. fluviatilis was only collected by night-biting catch. Non-vector species, An. turkhudi and An. moghulensis were collected by night-biting catch plus larval rearing (Table 1).

During the study, 839 third- and fourth-instar larvae were collected from 24 breeding sites in Bashagard; 6 Anopheles species were found: $A n$. culicifacies, An. dthali, An. stephensi, An. superpictus, An. moghulensis and An. turkhudi. The dominant species (30.5\%) was An. dthali, which was collected from all of sites. Details of the larval composition and localities are shown in Table 2.

\section{Susceptibility}

The susceptibility status of mosquito samples was determined according to WHO criteria: 98\%-100\% mortality indicates susceptibility, 80\%-97\% mortality indicates tolerance (requires confirmation of resistance with other methods) and $<80 \%$ mortality suggests resistance [21].

The susceptibility tests indicated that the field strain of An. stephensi exhibited $100 \%$ mortality and was susceptible to malathion, permethrin, lambda-cyhalothrin, cyfluthrin and deltamethrin (Table 3). This strain exhibited resistance to DDT and tolerance to dieldrin; mortality rates for these 2 insecticides were $53 \% \pm 2.05 \%$ and $86 \% \pm 1.34 \%$ respectively. The $\mathrm{LT}_{50}$ values of An. stephensi for DDT (4\%) and dieldrin (0.4\%) were 60.6 and 21.0 minutes respectively (Table 4).

Due to appearance of dieldrin tolerance and DDT resistance in this species, it was decided to plot the dose mortality regression line. An. stephensi were exposed at 15, 30, 60,120 minutes to a diagnostic dose of DDT $4 \%$ and dieldrin $0.4 \%$ to obtain 5\%-95\% mortality (Figure 3).

\section{Discussion}

This is the first formal entomological investigations in Bashagard district which sought to understand the distribution and composition of anopheline species in this area. During the study 7 Anopheles species were identified. The anopheline fauna on which we report is consistent with previous findings for Hormozgan province [4].

The most abundant adult anopheline mosquitoes were An. dthali, An. culicifacies and An. stephensi. Previous studies have shown that An. stephensi is a primary vector and other anopheline species, such as An. culicifacies, An. dthali, An. superpictus and An. fluviatilis, are secondary vectors in malaria transmission in Hormozgan [1-2,4,5,22-24].

An. dthali was the predominant Anopheline species, accounting for $41.7 \%$ and $30.5 \%$ of specimens in adults and larvae respectively. This result confirms what is reported in the literature that $A n$. dthali is predominant

\begin{tabular}{|c|c|c|c|c|c|c|c|c|}
\hline \multirow[t]{2}{*}{ Species } & \multirow[t]{2}{*}{ Village } & \multicolumn{5}{|c|}{ Collection method } & \multirow[t]{2}{*}{ No. } & \multirow[t]{2}{*}{$\%$} \\
\hline & & Pit shelter & Hand catch & Total catch & $\begin{array}{c}\text { Night- } \\
\text { biting catch }\end{array}$ & $\begin{array}{l}\text { Larval } \\
\text { rearing }\end{array}$ & & \\
\hline \multirow{2}{*}{ Anopheles culicifacies } & Tisur & 4 & 5 & 24 & 19 & 16 & 68 & 9.81 \\
\hline & Daranar & 7 & 11 & 25 & 26 & 31 & 100 & 14.43 \\
\hline \multirow{2}{*}{ An. dthali } & Tisur & 2 & 8 & 73 & 13 & 42 & 138 & 19.92 \\
\hline & Daranar & 3 & 6 & 82 & 31 & 29 & 151 & 21.79 \\
\hline \multirow{2}{*}{ An. fluviatilis } & Tisur & - & - & - & 8 & - & 8 & 1.16 \\
\hline & Daranar & - & - & - & 3 & - & 3 & 0.43 \\
\hline \multirow{2}{*}{ An. moghulensis } & Tisur & - & - & - & 4 & 31 & 35 & 5.05 \\
\hline & Daranar & - & - & - & 3 & 6 & 9 & 1.30 \\
\hline \multirow{2}{*}{ An. stephensi } & Tisur & 6 & 7 & 42 & 2 & 11 & 68 & 9.81 \\
\hline & Daranar & 3 & 5 & 21 & 4 & 15 & 48 & 6.93 \\
\hline \multirow{2}{*}{ An. superpictus } & Tisur & 5 & 4 & - & 6 & 3 & 18 & 2.59 \\
\hline & Daranar & 4 & 3 & 1 & 3 & 15 & 26 & 3.75 \\
\hline \multirow{2}{*}{ An. turkhudi } & Tisur & - & - & - & 10 & 2 & 12 & 1.73 \\
\hline & Daranar & - & 2 & - & 3 & 4 & 9 & 1.30 \\
\hline Total & & 34 & 51 & 268 & 135 & 205 & 693 & 100 \\
\hline
\end{tabular}




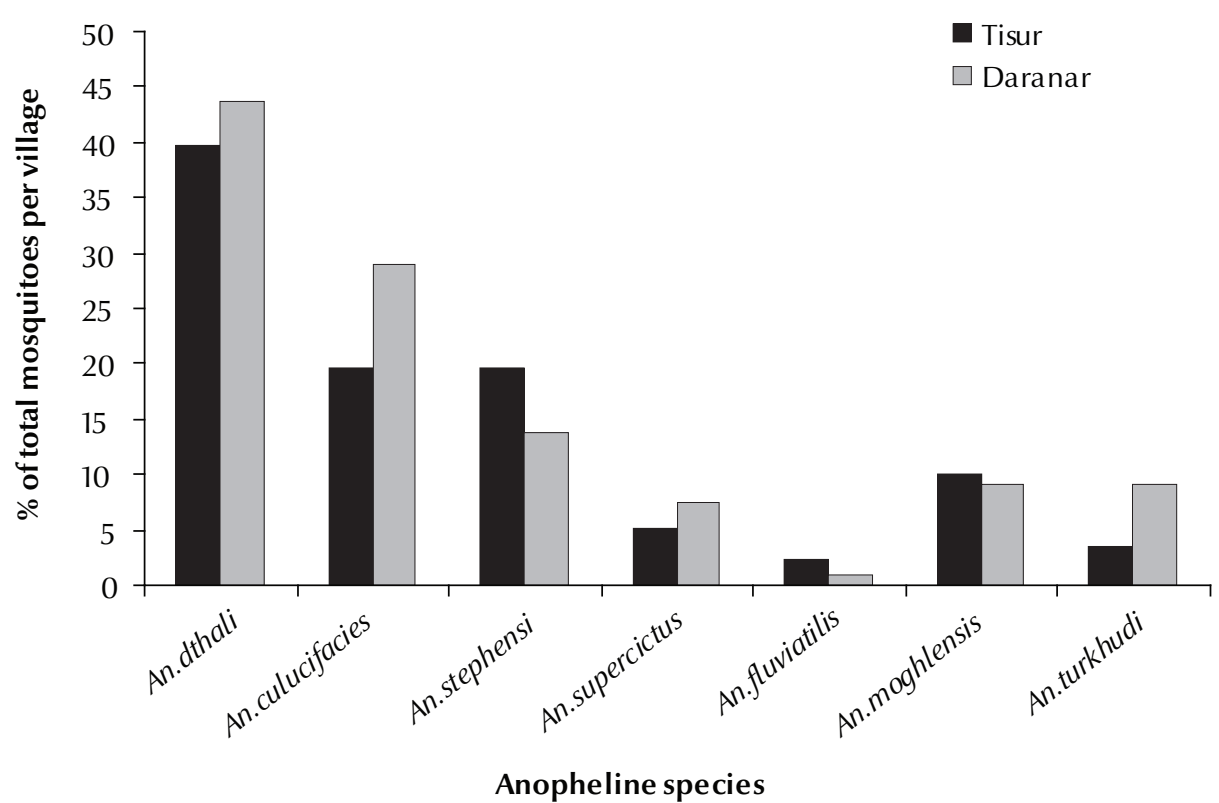

Figure 2 Prevalence of anopheline mosquitoes in 2 villages (Tisur and Daranar) in Bashagard district

anopheline mosquito in mountainous areas of Hormozgan province [23]. The species is considered a secondary vector in some parts of southern Islamic Republic of Iran, especially in the mountainous areas of Hormozgan province [24] and in northern regions of Somalia and Saudi Arabia [25].

Among the secondary vectors, An. culicifacies is considered a potential vector since its role in malaria transmission has been reported from Sistan and Baluchistan province in the south-east of the country bordering Afghanistan and Pakistan. This species is largely responsible for an epidemic of malaria in this province [26]. An. culicifacies as malaria vector is widely distribution in the Asia and Indian subcontinent [27]. The relative abundance of An. culicifacies in the present study is high compared with those of other studies conducted in Hormozgan province [4]. Similar abundance has been reported for this species from Ghassreghand, the neighbouring district to Bashagard [28].

Our data on An. stephensi agree with those of previous researchers, who have described this species being found together with An. fluviatilis, An. dthali, An. culicifacies, An. superpictus, An. turkhudi and An. mongolensis [29].

Previous studies indicate that $A n$. stephensi is a major malaria vector in
Hormozgan province. Sporozoite rates of samples from the south of the Islamic Republic of Iran were reported to be between $0.2 \%$ and $1.8 \%$ [5]. An. stephensi is one of the most important malaria vectors in India, Pakistan, Afghanistan, Iraq and Arabian Peninsula [29].

An. superpictus is known as a main malaria vector and the most widespread Anopheles species in the Islamic Republic of Iran. It is present in almost all parts of the country [7]. In our study, An. superpictus was collected from all the sites by different methods. This species has a broad geographical distribution in Asia, Europe and northern Africa, and evidence shows

\begin{tabular}{|c|c|c|c|c|}
\hline \multirow[t]{2}{*}{ Species } & \multirow{2}{*}{$\begin{array}{l}\text { Tisur } \\
\text { No. }\end{array}$} & \multirow{2}{*}{$\begin{array}{c}\text { Daranar } \\
\text { No. }\end{array}$} & \multicolumn{2}{|c|}{ Total } \\
\hline & & & No. & $\%$ \\
\hline Anopheles culicifacies & 40 & 163 & 203 & 24.2 \\
\hline An. dthali & 84 & 172 & 256 & 30.5 \\
\hline An. moghulensis & 20 & 21 & 223 & 26.6 \\
\hline An. stephensi & 28 & 43 & 71 & 8.5 \\
\hline An. superpictus & 12 & 22 & 34 & 4.1 \\
\hline An. turkhudi & 17 & 35 & 52 & 6.2 \\
\hline Total & 383 & 456 & 839 & 100 \\
\hline
\end{tabular}




\begin{tabular}{|c|c|c|c|c|c|c|}
\hline \multirow[t]{2}{*}{ Insecticide } & \multirow[t]{2}{*}{ Date } & \multirow{2}{*}{$\begin{array}{l}\text { Exposure time } \\
(\text { min) }\end{array}$} & \multicolumn{2}{|c|}{ Treatment } & \multicolumn{2}{|c|}{ Controla $^{\mathrm{a}}$} \\
\hline & & & $\begin{array}{l}\text { No. exposed } \\
\text { (replicates) }\end{array}$ & $\begin{array}{c}\text { Mortality rate } \\
(\%)\end{array}$ & $\begin{array}{l}\text { No. exposed } \\
\text { (replicates) }\end{array}$ & $\begin{array}{c}\text { Mortality rate } \\
(\%)\end{array}$ \\
\hline \multirow[t]{4}{*}{ DDT $4 \%$} & $14 / 02 / 10$ & 15 & $100(4)$ & 3 & $50(2)$ & 0 \\
\hline & $14 / 02 / 10$ & 30 & $100(4)$ & 7 & $50(2)$ & 0 \\
\hline & $16 / 02 / 10$ & 60 & $100(4)$ & 20 & $50(2)$ & 0 \\
\hline & $16 / 02 / 10$ & 120 & $100(4)$ & 49 & $50(2)$ & 0 \\
\hline \multirow[t]{4}{*}{ Dieldrin $0.4 \%$} & $18 / 02 / 10$ & 15 & $100(4)$ & 39 & $50(2)$ & 0 \\
\hline & $18 / 02 / 10$ & 30 & $100(4)$ & 61 & $50(2)$ & 0 \\
\hline & $20 / 02 / 10$ & 60 & $100(4)$ & 80 & $50(2)$ & 0 \\
\hline & $20 / 02 / 10$ & 120 & $100(4)$ & 99 & $50(2)$ & 0 \\
\hline Malathion 5\% & 10/08/09 & 60 & $100(4)$ & 100 & $50(2)$ & 0 \\
\hline \multirow[t]{3}{*}{ Permethrin $0.75 \%$} & $22 / 01 / 10$ & 60 & 100(4) & 100 & $50(2)$ & 0 \\
\hline & $31 / 12 / 09$ & 60 & $100(4)$ & 100 & $50(2)$ & 0 \\
\hline & 01/08/09 & 60 & $100(4)$ & 100 & $50(2)$ & 0 \\
\hline \multirow[t]{2}{*}{ Deltamethrin $0.05 \%$} & $10 / 01 / 10$ & 60 & $100(4)$ & 100 & $50(2)$ & 0 \\
\hline & 06/08/09 & 60 & $100(4)$ & 100 & $50(2)$ & 0 \\
\hline $\begin{array}{l}\text { Lamda-cyhalothrin } \\
0.05 \%\end{array}$ & 08/08/09 & 60 & $100(4)$ & 100 & $50(2)$ & 0 \\
\hline Cyfluthrin 0.15\% & 08/08/09 & 60 & $100(4)$ & 100 & $50(2)$ & 0 \\
\hline
\end{tabular}

${ }^{a}$ Fl progeny of An. stephensi reared from wild-caught females.

that An. superpictus is a main malaria vector in these regions [30].

An. fluviatilis was less abundant in the study area; only 11 females were captured in night-biting catch on donkeys. In a similar study carried out in the country, Naddaf et al. captured this species from outdoor habitats and on animal baits [31]. The low prevalence of An. fluviatilis might be attributed to the geography and environmental conditions of the district; this species mainly breeds in springs, pits around springs with or without vegetation, rainfall pits and coastal plains in other parts of Hormozgan province [32].

All species collected in our survey, except An. moghulensis and An. turkhudi, have been incriminated as malaria vectors in the Islamic Republic of Iran. How important this role might be will depend on their ability to achieve appreciable numbers, their host preference and their longevity.

As regards resistance, An. stephensi was resistant to DDT in Bashagard, tolerant to dieldrin but susceptible to all other insecticides. These finding confirm a previous study conducted in Hormozgan province [33] and another study conducted in Jiroft district, adjacent to Hormozgan province, which showed that this species was tolerant to DDT and dieldrin but susceptible to pyrethroid insecticides [12]. Studies of susceptibility tests on this species to insecticides in neighbouring countries showed resistance to DDT in Afghanistan, Pakistan, Iraq,

\begin{tabular}{|c|c|c|c|c|c|c|c|}
\hline \multirow[t]{2}{*}{ Insecticide } & \multirow[t]{2}{*}{ Intercept } & \multirow[t]{2}{*}{ B (SE) } & \multicolumn{2}{|c|}{ 95\% Cl (minutes) } & \multirow[t]{2}{*}{$\chi^{2}(\mathrm{df})^{\mathrm{a}}$} & \multirow[t]{2}{*}{ Mortality (\%) } & \multirow[t]{2}{*}{ Susceptibility } \\
\hline & & & $\mathbf{L T}_{50}$ & $\mathrm{LT}_{90}$ & & & \\
\hline \multirow[t]{3}{*}{ DDT } & -3.59 & $2.02(0.22)$ & 72.48 & 427.77 & $2.06(2)$ & 53 & Resistant \\
\hline & & & 60.62 & 262.07 & & & \\
\hline & & & 51.89 & 188.39 & & & \\
\hline \multirow[t]{3}{*}{ Dieldrin } & -3.34 & $2.53(0.26)$ & 24.24 & 87.02 & $2.69(2)$ & 86 & Tolerant \\
\hline & & & 21.00 & 67.50 & & & \\
\hline & & & 17.59 & 56.17 & & & \\
\hline
\end{tabular}

${ }^{a} P=0.05$.

${ }^{b}$ Exposure time $=60$ minutes.

$S E=$ standard error; $C I=$ confidence interval; $L T=$ lethal time; $d f=$ degrees offreedom . 

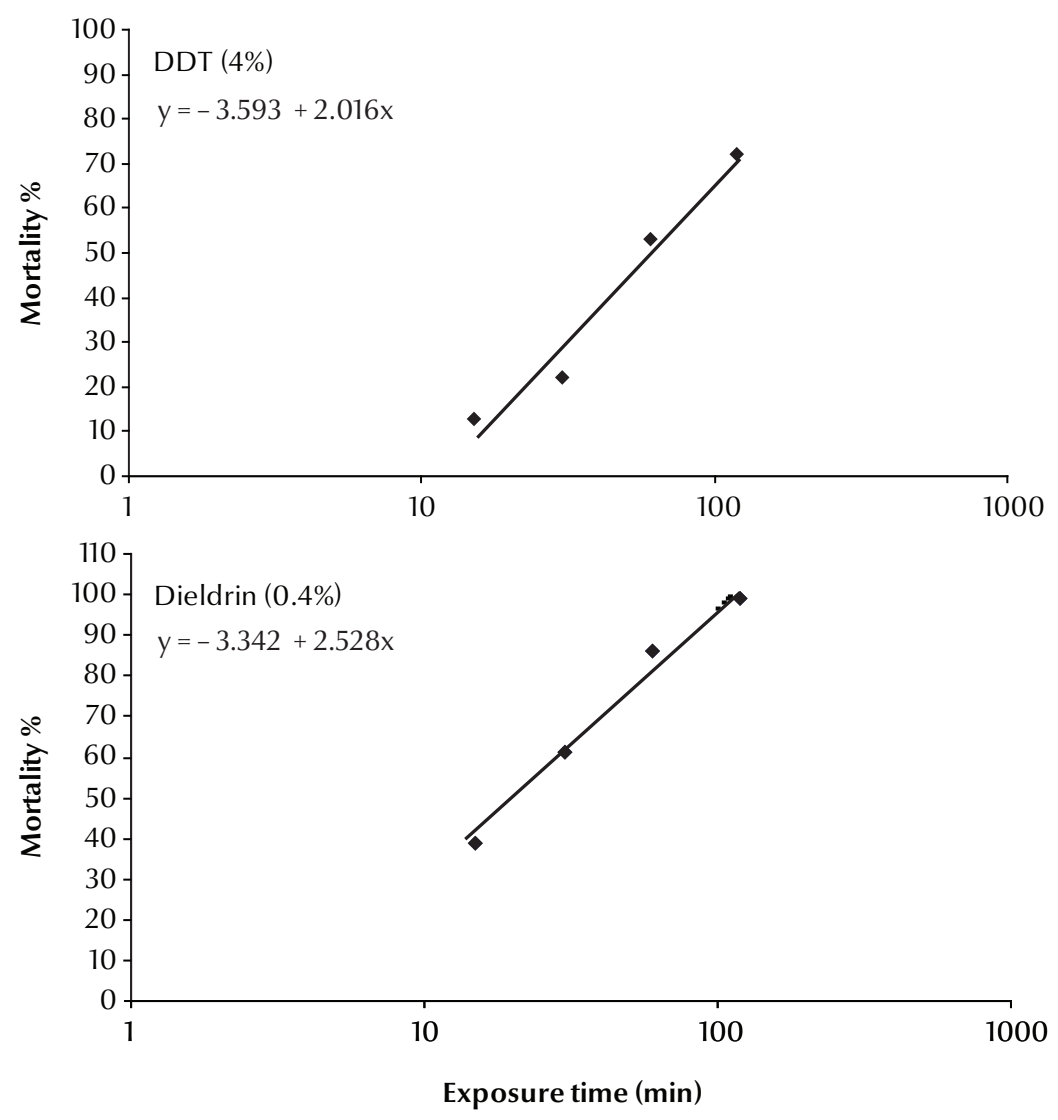

Figure 3 Regression line of mortality of Anopheles stephensi exposed to DDT $4 \%$ and dieldrin $0.4 \%$ at different interval times in Bashagard

Oman, United Arab Emirates and Saudi Arabia [10].

An. stephensi is sufficiently endophilic and endophagic to come into contact with insecticide residue in houses and therefore insecticide resistance in this species can be explained by the widespread use of DDT housespraying applications in several districts of the country during the malaria eradication campaign in the 1950s. There is no report of cross-resistance between DDT and pyrethroid yet. However, recently there is an indication of pyrethroid resistance in An. stephensi in the adjacent area of the Hormozgan province [34].

\section{Conclusion}

The success of vector control programmes is highly dependent on precise information about fauna and distribution of the anopheline mosquitoes that are involved in malaria transmission in the region. Identification of the vector species is required for the development of effective vector control strategy that is based principally on LLINs.

The current findings will help decision-making in the national malaria control programme, especially in the choice of insecticide to use during the next campaigns of LLINs in Bashagard district. Monitoring of pyrethroid resistant in the region is highly recommended.

\section{Acknowledgements}

The authors appreciate the collaboration received from Dr Arab-Behjat, Head of Bashagard Health Centre for providing facilities for implementation of this investigation. We also thank
Mr M. Baghaei, Mr S. Zarei, Mr H. Haghshenas, Mr B. Ferdoosi and Mrs M. Karimi personnel of the Rudan Health Center for their cooperation in the field.

The authors thank Mr H. Javedan from the WHO Malaria Training Centre in Bandar Abbas for his excellent assistance and rearing of specimens.

This investigation received financial support from School of Public Health, Tehran University of Medical Sciences, Ministry of Health \& Medical Education (Center for Disease Control) and the Research Deputy of Hormozgan University of Medical Sciences.

This study was conducted by the first author (M. Soleimani-Ahmadi) as part of the requirement to attain a $\mathrm{PhD}$ from the Tehran University of Medical Sciences. 


\section{References}

1. Hanafi-Bojd AA et al. Entomological and epidemiological atg tributes for malaria transmission and implementation of vector control in southern Iran. Acta Tropica, 2012, 121(2):85-92.

2. Hanafi-Bojd AA et al. Spatio-temporal distribution of malaria vectors (Diptera: Culicidae) across different climatic zones of Iran. Asian Pacific Journal of Tropical Medicine, 2011, 4(6):498-504.

3. Raeisi A et al. The trend of malaria in I.R. Iran from 2002 to 2007. Hakim Research Journal, 2009, 12(1):35-41 [In Persian with English abstract].

4. Oshaghi MA et al. Anopheles stephensi biological forms, geographical distribution, and malaria transmission in malarious regions in Iran. Pakistan Journal of Biological Science, 2006, 9(2):294-298.

5. Vatandoost $\mathrm{H}$ et al. Larval habitats of main malaria vectors in Hormozgan province and their susceptibility to different larvicides. Southeast Asian Journal of Tropical Medicine and Public Health, 2004, 35(Suppl. 2):22-25.

6. Vatandoost $\mathrm{H}$ et al. Bionomics of Anopheles stephensi Liston in the malarious area of Hormozgan province, southern Iran, 2002. Acta Tropica, 2006, 97(2):196-203.

7. Oshaghi MA et al. The Anopheles superpictus complex: introduction of a new malaria vector complex in Iran. Bulletin de la Société de Pathologie Exotique, 2008, 101(5):429-434.

8. Naddaf SR et al. Molecular characterization of Anopheles fluviatilis species complex in the Islamic Republic of Iran. Eastern Mediterranean Health Journal, 2003, 9(3):257-265.

9. Davari B et al. Selection of Anopheles stephensi with DDT and dieldrin and cross-resistance spectrum to pyrethroids and fipronil. Pesticide Biochemistry and Physiolology, 2007, 89(2): 97-103.

10. Vector resistance to pesticides: fifteenth report of the WHO Expert Committee on Vector Biology and Control Imeeting held in $\mathrm{Ge}$ neva from 5 to 12 March 1991]. Geneva, World Health Organization, 1992 (WHO Technical Report Series, No. 818).

11. Manouchehri AV, Yaghoobi-Ershadi MR. Propoxur susceptibility test of Anopheles stephensi in southern Islamic Republic of Iran during 1976-86. Journal of the American Mosquito Control Association, 1988, 4(2):159-162.

12. Abai MR et al. Comparative performance of imagicides on Anopheles stephensi, main malaria vector in a malarious area, southern Iran. Journal of Vector Borne Diseases, 2008, 45(4):307-312.

13. Vatandoost $\mathrm{H}$ et al. Monitoring of insecticides resistance in main malaria vectors in a malarious area of Kahnooj district, Kerman province, southeastern Iran. Journal of Vector Borne Diseases, 2005, 42(3):100-108.

14. Soleimani Ahmadi $\mathrm{M}$ et al. Effects of educational intervention on long-lasting insecticidal nets use in a malarious area, southeast Iran. Acta Medica Iranica, 2012, 50(4):279-287.

15. Soleimani-Ahmadi $M$ et al. Field evaluation of permethrin long-lasting insecticide treated nets (Olyset ${ }^{\circ}$ ) for malaria control in an endemic area, south-east of Iran. Acta Tropica, 2012, 123(3):146-153.

16. Manual on practical entomology in malaria. Part II. Methods and techniques. Geneva, World Health Organization, 1975.

17. Shahgudian ER. A key to the anophelines of Iran. Acta Medica Iranica, 1960, 3:38-48.
18. Malaria entomology and vector control. Geneva, World Health Organization, 2002.

19. Abbott WS. A method of computing the effectiveness of an insecticide. Journal of Economic Entomology, 1925, 18:265-267.

20. Finney DJ. Probit analysis, 3rd ed. Cambridge, Cambridge University Press, 1971.

21. Resistance of vectors and reservoirs of disease to pesticides : tenth report of the WHO Expert Committee on Vector Biology and Control [meeting held in Geneva from 5 to 11 November 1985].Geneva, World Health Organization, 1986 (WHO Technical Report Series, No. 737).

22. Hanafi-Bojd AA, Vatandoost $\mathrm{H}$, Jafari R. Susceptibility status of An. dthali and An. fluviatilis to commonly used larvicides in an endemic focus of malaria, southern Iran. Journal of Vector Borne Diseases, 2006, 43(1):34-38.

23. Vatandoost $\mathrm{H}$ et al. Ecology of Anopheles dthali Patton in Bandar abbas district, Hormozgan province, southern Iran. Iranian Journal of Arthropod-Borne Diseases, 2007, 1(1):27-33.

24. Manouchehri AV, Ghiasseddin M, Shahgudian ER. Anopheles dthali Patton, 1905, a new secondary vector in southern Iran. Annals of Tropical Medicine and Parasitology, 1972, 66:537538.

25. Rishikesh N. Anopheles dthali Patton as a possible secondary vector of malaria in the northern region of the Somalia Republic. Geneva, World Health Organization, 1961.

26. Vatandoost $\mathrm{H}$ et al. Ecology of malaria vector Anopheles Culicifacies in a malarious area of Sistan va Baluchestan province, south-east Islamic Republic of Iran. Eastern Mediterranean Health Journal, 2011, 17(5):439-445.

27. Subbarao SK. The Anopheles culicifacies complex and control of malaria. Parasitology Today (Personal Ed.), 1988, 4:2-5.

28. Zaim $\mathrm{M}$ et al. Cyfluthrin (EW 050)-impregnated bednets in a malaria control program in Ghassreghand (Baluchistan, Iran). Journal of the American Mosquito Control Association, 1998, 14(4):421-430.

29. Vatandoost $\mathrm{H}$, Hanafi-Bojd AA. Current resistant status of Anopheles stephensi Liston to different larvicides in Hormozgan province, south-eastern Iran. Pakistan Journal of Biological Sciences, 2005, 8(11):1568-1570.

30. Nejati J et al. Susceptibility/Resistance of malaria vector, Anopheles superpictus Grassi to different insecticides in a malarious area, south-eastern Iran. Asian Pacific Journal of Tropical Medicine, 2012 [In press].

31. Naddaf SR et al. Confirmation of two sibling species among Anopheles fluviatilis mosquitoes in southern Iran by analysis of cytochrome oxidase I gene. Iranian Journal of Arthropod-Borne Diseases, 2011 [In press].

32. Vatandoost $\mathrm{H}$ et al. Larval habitats of main malaria vectors in Hormozgan province and their susceptibility to different larvicides. Southeast Asian Journal of Tropical Medicine and Public Health, 2004, 35:22-25.

33. Hanafi-Bojd AA et al. Larval habitats and biodiversity of anopheline mosquitoes (Diptera:Culicidae) in a malarious area of southern Iran. Journal of Vector-Borne Diseases, 2012, 49(2):91-100.

34. Vatandoost $\mathrm{H}$, Hanafi-Bojd AA. Indication of pyrethroid resistd ance in the main malaria vector, Anopheles stephensi from Iran. Asian Pacific Journal of Tropical Medicine, 2012, 5(9):722-726. 